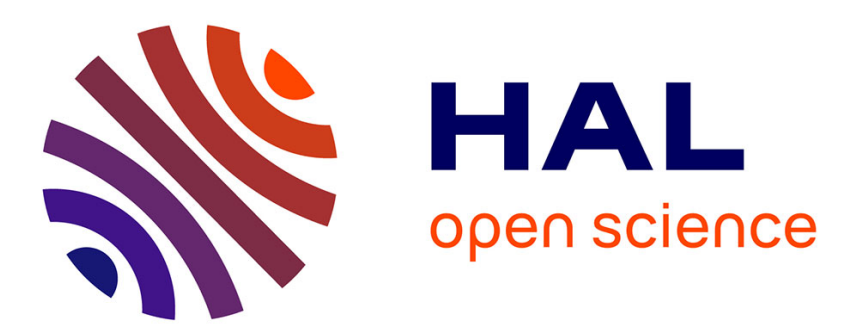

\title{
Compatible volume and taper models for economically important tree species of Turkey
}

Özçelik, John Brooks

\section{To cite this version:}

Özçelik, John Brooks. Compatible volume and taper models for economically important tree species of Turkey. Annals of Forest Science, 2012, 69 (1), pp.105-118. 10.1007/s13595-011-0137-4 . hal00930708

\section{HAL Id: hal-00930708 \\ https://hal.science/hal-00930708}

Submitted on 1 Jan 2012

HAL is a multi-disciplinary open access archive for the deposit and dissemination of scientific research documents, whether they are published or not. The documents may come from teaching and research institutions in France or abroad, or from public or private research centers.
L'archive ouverte pluridisciplinaire HAL, est destinée au dépôt et à la diffusion de documents scientifiques de niveau recherche, publiés ou non, émanant des établissements d'enseignement et de recherche français ou étrangers, des laboratoires publics ou privés. 


\title{
Compatible volume and taper models for economically important tree species of Turkey
}

\author{
Ramazan Özçelik • John R. Brooks
}

Received: 27 June 2011 / Accepted: 9 September 2011 /Published online: 7 October 2011

(C) INRA and Springer-Verlag, France 2011

\begin{abstract}
- Introduction The accurate estimation of stem taper and volume are crucial for the efficient management of the forest resources. Compatible segmented polynomial taper and volume equations were developed for Brutian pine (Pinus brutia Ten.), Lebanon cedar (Cedrus libani A. Rich.), Cilicica fir (Abies cilicica Carr.), Scots pine (Pinus sylvestris L.), and Black pine (Pinus nigra Arnold.).

- Methods In this study, the Clark et al. (USDA For Serv Res Pap SE-282, 1991) segmented taper model was selected as this model is one of the most tested segmented models and has frequently been well ranked for its excellent performance. The data for each species were divided into two sets: the majority (about 75\%) was used to estimate model parameters, and the remaining data (about 25\%) were reserved to validate the models. The performance of the models was compared and evaluated by average bias, standard error of the estimate (SEE), and a fit index (FI).

- Results The proposed model generally performed better than the other equations for the whole tree as well as for sections within the tree, based on the ten relative height classes examined. In addition, tree bole volume estimates were compared to other established tree bole volume estimation techniques.
\end{abstract}

\section{Handling Editor: Barry Alan Gardiner}

Contribution of the co-authors Dr. John Brooks, contributed to selection of methods, evaluation of results, and response to comments of reviewers.

\section{R. Özçelik $(\bowtie)$}

Faculty of Forestry, Süleyman Demirel University,

East Campus,

32260 Isparta, Turkey

e-mail: ramazanozcelik@sdu.edu.tr

\section{J. R. Brooks}

Forest Biometrics, Division of Forestry and Natural Resources,

West Virginia University,

322 Percival Hall,

Morgantown, WV 26506-6125, USA
- Conclusion Based on our results, the taper equation of Clark et al. (1991) is recommended for estimating diameter at a specific height, height to a specific diameter, merchantable volume, and total volume for the species considered.

Keywords Segmented models $\cdot$ Form-class profile $\cdot$ Taper . Volume $\cdot$ Turkey

\section{Introduction}

Brutian pine (Pinus brutia Ten.), Scots pine (Pinus sylvestris L.), Lebanon cedar (Cedrus libani A. Rich.), Cilicica fir (Abies cilicica Carr.), and Black pine (Pinus nigra Arnold.) are major commercial tree species in Turkey. There are nearly 11.64 million ha of commercial Brutian pine (about 5.4 million ha), Scots pine (1.24 million ha), Lebanon cedar (about 0.5 million ha), Cilicica fir (about 0.3 million ha), and Black pine (4.2 million ha) forest in Turkey, accounting for almost half of the total forest land with a current standing volume of approximately 750 million $\mathrm{m}^{3}$ (Anonymous 2006). These tree species are an important source of raw material for the forest products industry in Turkey.

With ever-changing market conditions, there is a need to accurately estimate tree volumes to different upper stem merchantability limits. This is not currently possible with the existing local volume tables for these five species. One of the most accurate approaches to estimating upper stem diameter and volume to any merchantability limit is through the use of compatible volume and taper models (Kozak 2004; Jiang et al. 2005). Although merchantable volume equations developed from volume-ratio equations are very easy to use and develop, those obtained from taper functions are generally preferred probably because they also allow estimation of diameter at a given height (Dieguez-Aranda et al. 2006). As reported by Li and Weiskittel (2010); the advantage of estimating volume through taper equations over 
existing volume tables lies in the ability of taper equations to accurate predict total height (th) diameter over bark (dob) or diameter inside bark (dib) at any given height of individual trees, hence allowing the acquisition of merchantable volume information to any desired specification.

Numerous tree taper models of various forms and complexity have been published (Max and Burkhart 1976; Kozak 1988; Thomas and Parresol 1991; Newnham 1992; Fang et al. 2000; Lee et al. 2003) indicating the importance of the subject in forest management and at least two approaches are used with success today. One expresses variable form as a single continuous polynomial. The other expresses variable form utilizing a segmented polynomial in such a way that bole is divided into segments which are then joined at inflection points between segments (Fang and Bailey 1999).

Taper systems do not have widespread use in Turkey and different standard volume equations developed (Alemdağ 1962, 1967; Evcimen 1963; Gulen 1959) over five decades ago are still the most common tool used for estimating the volume of the five tree species described in this paper. Several studies have been carried out to test the suitability of different taper models for describing the stem profile and predicting stem volume of different tree species at the regional level in Turkey (Yavuz and Saraçoğlu 1999; Sakıcı et al. 2008; Brooks et al. 2008). However, additional work is needed in this area to refine volume estimation. As reported by Kozak and Smith (1993): a well behaved taper equation should not only give unbiased estimates of dib or dob with minimum variance, but also have flexibility to adapt to a wide variety of species and give accurate predictions of stem volume. Therefore, it is necessary and beneficial to further study the characteristics of taper equations and extend their use to other species besides the ones for which they were originally developed.

Ideally, a volume estimation system should be compatible, i.e., the volume of the tree bole is obtained through the integration of the taper model from the ground to the top of the bole and should be equal to the actual stem volume (Demaerschalk 1972; Clutter 1980). A total volume equation is very easy to use and is therefore preferred when classification of the products by merchantable size is not required. In comparison with single and segmented taper models, a variable-form taper model usually provides the lowest degree of local bias and the greatest precision in taper predictions (Kozak 1988; Newnham 1992; Sharma and Zhang 2004). However, the disadvantages of variable-form taper models are that they cannot be integrated analytically to calculate total stem or log volume and merchantable height for a given top diameter; it must be obtained by iteration (Kozak and Smith 1993).

Jiang et al. (2005) reported that segmented polynomial models appear to be more accurate than other model formulations for estimating diameter, height, and volume estimation. In this study, we used this second approach to develop a segment stem taper model based on form-class segmented taper model presented by Clark et al. (1991). Several studies have compared some of the more commonly employed taper models. For example, Clark et al. (1991) found that their form-class profile model was superior to the Max and Burkhart (1976) model, the Cao et al. (1980) model, and Schlaegel's (1983) form class model. Figueiredo-Filho et al. (1996) evaluated five taper models for estimating diameters along the stem for predicting merchantable or total volume. Most of the statistics indicated that the segmented form-class model of Clark et al. (1991) performed best for describing the stem profile and predicting stem volume in their study. $\mathrm{Li}$ and Weiskittel (2010) compared ten widely used stem taper profile models for predicting both diameter and total stem volume in the Acadian Region of North America. They found that the segmented taper equation of Clark et al. (1991) provided the best predictions across all species when upper stem diameter measurements were available for stem volume.

The objective of this research was to develop a compatible volume system based on the Clark et al. (1991) taper model form that accurately describes the stem profile throughout the main bole and provides accurate estimates of the tree volume to any upper stem merchantability limit for five commercially important tree species in Turkey. We evaluated a widely recognized, reliable, and flexible taper model form published by Max and Burkhart (1976). In addition, total tree volume estimates, based on the proposed models, were compared to existing total stem volume tables and the combined variable equation of Spurr (1952) which was fit to the same data.

\section{Materials and methods}

In total 248 Brutian pine, 124 Lebanon cedar, 196 Cilicica fir, and 162 Black pine were felled in even-aged forest areas of Isparta Forest Region and 95 Scots pine were felled in evenaged forest areas of Erzurum Forest Regions in Turkey, on land owned by The Turkish Forest Service. Sample trees were selected to ensure a representative distribution from both the dominant and co-dominant crown classes across a range of height and diameter classes in even-aged sawn-timber stands. Trees possessing multiple stems, broken tops, obvious cankers or crooked boles were not included in the sample. Trees were felled and total height was measured to the nearest $0.03 \mathrm{~m}$. Diameter over bark (dob) at breast height $(1.3 \mathrm{~m})$ was measured and recorded to the nearest $0.25 \mathrm{~cm}$. Diameter over bark was also measured at $0.3,2.3 \mathrm{~m}$ and then at intervals of $1 \mathrm{~m}$ along the remainder of the stem. In each section, two perpendicular diameters over bark were measured and then arithmetically averaged. Actual volumes and section volumes in cubic meters were calculated using the overlapping bolts method as described by Bailey (1995). 
The scatter plot of relative diameter against relative height was examined visually for each species to detect possible anomalies in data. Extreme data points were observed in all species, therefore the systematic approach, proposed by $\mathrm{Bi}$ (2000) for detecting abnormal data points was applied to increase the efficiency of the process. This involved local quadratic fitting with a smoothing parameter of 0.25 for all species, which was selected after iterative fitting and visual examination of the smoothed taper curves overlaid on the data. Using this approach, the number of extreme values accounted for less than $0.2 \%$ of data for all species. The plots of relative height against relative diameter used for this study, together with the loess regression line, are shown in Fig. 1. Approximately 25\% of sample trees were selected at random and used as the validation data set, while the rest were used for model fitting. All trees with total height less than $5.3 \mathrm{~m}$ were eliminated because they could not be used to fit the Clark et al. (1991) model. Summary statistics for the both data sets are shown in Tables 1 and 2.

The following notation will be used hereafter. Other definitions specific to a particular equation will be listed with the equation:

$D \quad$ is diameter at breast height $(1.3 \mathrm{~m}$ above ground) over bark $(\mathrm{cm})$

$d \quad$ is diameter over bark (dob) at height $h(\mathrm{~cm})$

$H \quad$ is total tree height $(\mathrm{m})$
Fig. 1 Plot of relative height versus relative diameter over bark for each species studied
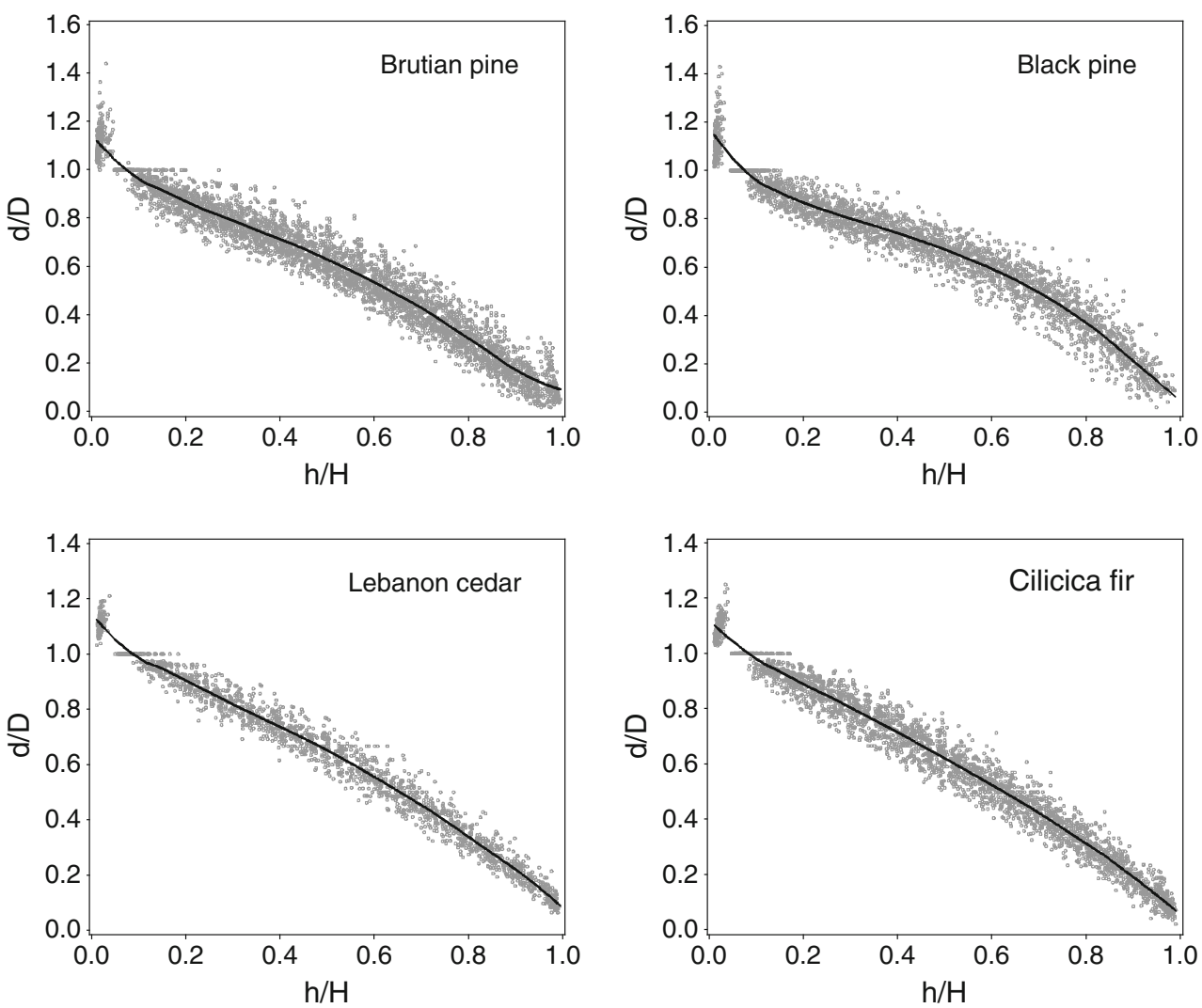

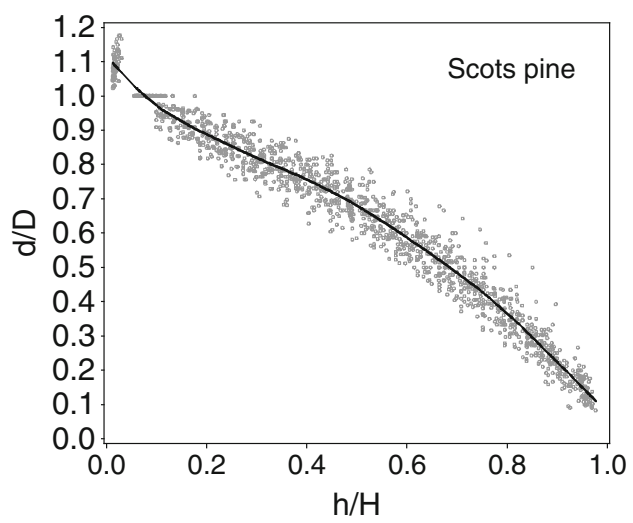


Table 1 Model fitting data summary statistics

\begin{tabular}{|c|c|c|c|c|}
\hline Species & Mean & $\mathrm{SD}$ & Minimum & Maximum \\
\hline \multicolumn{5}{|c|}{ Brutian Pine $(\mathrm{n}=183$ trees $)$} \\
\hline DBH $(\mathrm{cm})$ & 38.19 & 13.20 & 12.00 & 75.00 \\
\hline Total height (m) & 18.48 & 4.80 & 6.50 & 26.50 \\
\hline Disk dob (cm) & 23.27 & 13.54 & 1.00 & 79.00 \\
\hline Disk height (m) & 8.95 & 5.94 & 0.30 & 26.30 \\
\hline \multicolumn{5}{|c|}{ Lebanon cedar $(n=95$ trees $)$} \\
\hline $\mathrm{DBH}(\mathrm{cm})$ & 31.32 & 7.08 & 14.00 & 62.00 \\
\hline Total height (m) & 15.67 & 3.35 & 7.80 & 25.90 \\
\hline Disk dob (cm) & 19.18 & 16.45 & 3.00 & 64.00 \\
\hline Disk height (m) & 8.14 & 5.17 & 0.30 & 25.30 \\
\hline \multicolumn{5}{|c|}{ Cilicica fir ( $\mathrm{n}=153$ trees $)$} \\
\hline $\mathrm{DBH}(\mathrm{cm})$ & 34.50 & 12.35 & 14.00 & 70.00 \\
\hline Total height (m) & 15.82 & 19.24 & 7.60 & 27.30 \\
\hline Disk dob (cm) & 20.44 & 19.24 & 1.00 & 74.00 \\
\hline Disk height (m) & 8.35 & 5.52 & 0.30 & 26.30 \\
\hline \multicolumn{5}{|c|}{ Scots Pine $(n=76$ trees $)$} \\
\hline $\mathrm{DBH}(\mathrm{cm})$ & 28.88 & 7.74 & 15.00 & 44.00 \\
\hline Total height (m) & 17.04 & 3.80 & 9.80 & 25.00 \\
\hline Disk dob (cm) & 17.80 & 14.62 & 3.00 & 46.00 \\
\hline Disk height (m) & 8.64 & 5.51 & 0.30 & 24.30 \\
\hline \multicolumn{5}{|c|}{ Black pine $(\mathrm{n}=121$ trees $)$} \\
\hline DBH $(\mathrm{cm})$ & 33.93 & 13.07 & 14.00 & 66.00 \\
\hline Total height (m) & 19.58 & 4.40 & 9.00 & 29.00 \\
\hline Disk dob (cm) & 22.42 & 12.65 & 2.00 & 68.00 \\
\hline Disk height (m) & 9.23 & 6.02 & 0.30 & 27.30 \\
\hline
\end{tabular}

$h$ is height above the ground to the measurement point (m)

$V \quad$ is total stem volume over bark from stump $\left(\mathrm{m}^{3}\right)$

$r, c, e \quad$ are regression coefficients for heights below $1.3 \mathrm{~m}$

$p \quad$ is regression coefficient for heights between $1.3 \mathrm{~m}$ and $5.3 \mathrm{~m}$

$a$ and $b$ are regression coefficients for heights above $5.3 \mathrm{~m}$

$F \quad$ is diameter over bark (dob) at $5.3 \mathrm{~m}$ above ground $(\mathrm{cm})$

$\beta_{1}-\beta_{4} \quad$ are coefficients to be estimated

$k \quad$ is equal to $\pi / 40,000$, a metric constant for converting from diameter squared in square centimeters to cross-sectional area in square meters

$a_{0}, a_{1} \quad$ are regression coefficients

$b_{1}, b_{2} \quad$ are regression coefficients
2.1 Taper and volume equations

Clark et al. (1991) developed a form-class segmented profile model combining the better attributes of Schlaegel's and Max and Burkhart's models.

(1) Butt section, from stump to $1.3 \mathrm{~m}$

(2) Lower stem, from $1.3 \mathrm{~m}$ to $5.3 \mathrm{~m}$

(3) Middle stem, from $5.3 \mathrm{~m}$ to $40-70 \%$ of total height

(4) Upper stem, from $40 \%$ to $70 \%$ of total height to the tip of the tree

A Schlaegel-type equation is used to estimate diameter in the butt, a Schlaegel form-class equation is used in the lower stem, while an equation of the Max and Burkhart type is used for the other sections.

The Clark et al. (1991) taper function has the following form:

$d=\left\{\begin{array}{l}I_{\mathrm{S}}\left[D^{2}\left(1+\frac{\left(c+e / D^{3}\right)\left((1-h / H)^{r}-(1-1.30 / H)^{r}\right)}{1-(1-1.30 / H)^{r}}\right]+\right. \\ I_{\mathrm{B}}\left[D^{2}-\frac{\left(D^{2}-F^{2}\right)\left((1-1.30 / H)^{p}-(1-h / H)^{p}\right)}{(1-1.30 / H)^{p}-(1-5.30 / H)^{p}}\right]+ \\ I_{\mathrm{T}}\left[F^{2}\left(b\left(\frac{h-5.30}{H-5.30}-1\right)^{2}+I_{\mathrm{M}}\left(\frac{1-b}{a^{2}}\right)\left(a-\frac{h-5.30}{H-5.30}\right)^{2}\right)\right]\end{array}\right\}^{0.5}$

Table 2 Model validation data summary statistics

\begin{tabular}{lrrrr}
\hline Species & Mean & \multicolumn{1}{c}{ SD } & Minimum & Maximum \\
\hline Brutian Pine (n=65 & trees) & & & \\
DBH (cm) & 39.96 & 14.49 & 14.00 & 71.00 \\
Total height (m) & 18.52 & 4.35 & 7.50 & 26.70 \\
Disk dob (cm) & 24.32 & 14.58 & 1.00 & 75.00 \\
Disk height (m) & 8.95 & 5.82 & 0.30 & 25.30 \\
Lebanon cedar (n=29 trees) & & & \\
DBH (cm) & 31.25 & 6.32 & 21.00 & 46.00 \\
Total height (m) & 15.92 & 3.36 & 9.60 & 23.70 \\
Disk dob (cm) & 19.19 & 16.30 & 3.00 & 50.00 \\
Disk height (m) & 8.24 & 5.23 & 0.30 & 23.30 \\
Cilicica fir (n=43 trees) & & & \\
DBH (cm) & 36.83 & 14.63 & 15.00 & 73.00 \\
Total height (m) & 16.27 & 5.05 & 8.00 & 26.00 \\
Disk dob (cm) & 21.74 & 21.00 & 1.00 & 76.00 \\
Disk height (m) & 8.74 & 5.85 & 0.30 & 25.30 \\
Scots pine (n=21 trees) & & & \\
DBH (cm) & 30.64 & 6.49 & 18.00 & 43.50 \\
Total height (m) & 16.82 & 3.46 & 11.80 & 22.20 \\
Disk dob (cm) & 17.36 & 14.30 & 3.00 & 43.00 \\
Disk height (m) & 8.47 & 5.35 & 0.30 & 21.30 \\
Black pine (n=41 trees) & & & \\
DBH (cm) & 31.80 & 11.06 & 13.00 & 54.00 \\
Total height (m) & 19.32 & 4.89 & 9.50 & 27.20 \\
Disk dob (cm) & 20.82 & 11.18 & 2.00 & 59.00 \\
Disk height (m) & 9.20 & 6.12 & 0.30 & 26.30 \\
\hline & & & & \\
\hline
\end{tabular}


The volume equation, derived through integration of the Clark et al. (1991) taper equation, is of the form:

$V=k\left\{\begin{array}{l}I_{1} D^{2}\left[(1-G W)\left(U_{1}-L_{1}\right)+\frac{W\left(\left(1-L_{1} / H\right)^{r}\left(H-L_{1}\right)-\left(1-U_{1} / H\right)^{r}\left(H-U_{1}\right)\right)}{(r+1)}\right] \\ +I_{2} I_{3}\left[\begin{array}{l}\left.T\left(U_{2}-L_{2}\right)+\frac{Z\left(\left(1-L_{2} / H\right)^{p}\left(H-L_{2}\right)-\left(1-U_{2} / H\right)^{p}\left(H-U_{2}\right)\right)}{(p+1)}\right] \\ {\left[\begin{array}{l}b\left(U_{3}-L_{3}\right)-\frac{b\left(\left(U_{3}-5.30\right)^{2}-\left(L_{3}-5.30\right)^{2}\right)}{(H-5.30)} \\ +\frac{b / 3\left(\left(U_{3}-5.30\right)^{3}-\left(L_{3}-5.30\right)^{3}\right)}{(H-5.30)^{2}}\end{array}\right.} \\ +I_{4} F^{2}\left[\begin{array}{l}I_{5}(1 / 3)\left(1-b / a^{2}\right)\left(a(H-5.30)-\left(L_{3}-5.30\right)\right)^{3} \\ (H-5.30)^{2}\end{array}\right. \\ -\frac{I_{6}(1 / 3)\left(1-b / a^{2}\right)\left(a(H-5.30)-\left(U_{3}-5.30\right)\right)^{3}}{(H-5.30)^{2}}\end{array}\right.\end{array}\right\}$

Four indicator variables for taper function were defined as follows:

$I_{\mathrm{S}}=\left\{\begin{array}{ll}1 & h<1.30 \\ 0 & \text { otherwise }\end{array}, I_{\mathrm{B}}=\left\{\begin{array}{ll}1 & 1.30 \leq h<5.30 \\ 0 & \text { otherwise }\end{array}\right.\right.$,
$I_{\mathrm{T}}=\left\{\begin{array}{ll}1 & h>5.30 \\ 0 & \text { otherwise }\end{array}, \quad I_{\mathrm{M}}= \begin{cases}1 & h<\left(5.30+b_{5}(H-5.30)\right) \\ 0 & \text { otherwise }\end{cases}\right.$

The combined variables used in this model are as follows:

$G=\left(1-\frac{1.30}{H}\right)^{r}, \quad W=\frac{\left(c+e / D^{3}\right)}{1-G}, x=\left(\frac{1-1.30}{H}\right)^{p}, y=\left(1-\frac{5.30}{H}\right)^{p}, \quad z=\frac{\left(D^{2}-F^{2}\right)}{(x-y)}$

$T=D^{2}-Z X, L_{1}=\max (L, 0.30), \quad L_{2}=\max (L, 1.30), \quad L_{3}=\max (L, 5.30), \quad U_{1}=\min (U, 1.30), \quad U_{2}=\min (U, 5.30), \quad U_{3}=\min (U, H)$

The following indicator variables were used for the volume model:

$I_{1}=\left\{\begin{array}{ll}1 & L<1.30 \\ 0 & \text { otherwise }\end{array}, \quad I_{2}=\left\{\begin{array}{ll}1 & L<5.30 \\ 0 & \text { otherwise },\end{array} I_{3}=\left\{\begin{array}{ll}1 & U>1.30 \\ 0 & \text { otherwise },\end{array} \quad I_{4}= \begin{cases}1 & U>5.30 \\ 0 & \text { otherwise }\end{cases}\right.\right.\right.$

$I_{5}=\left\{\begin{array}{ll}1 & \left(L_{3}-5.30\right)<b_{5}(H-5.30) \\ 0 & \text { otherwise }\end{array}, I_{6}= \begin{cases}1 & \left(U_{3}-5.30\right)<b_{5}(H-5.30) \\ 0 & \text { otherwise }\end{cases}\right.$

All other variables as previously defined.

Diameter at $5.30 \mathrm{~m}$ is a required input variable for these taper and volume equations. In this study, diameters at $5.30 \mathrm{~m}$ were initially obtained through actual field measurements (Model 1) and then predicted (Model 2) for each tree species using the proposed equation by Clark et al. (1991) (Eq. 3). The effect of utilizing a prediction function for this variable was evaluated as part of this study. Clark et al. (1991) proposed the following equation to estimate diameter at $5.30 \mathrm{~m}$ :

$F=D\left(b_{1}+b_{2}(5.30 / H)\right)^{2}$

Parameter estimates for Eq. 3 and Models (1) and (2) are displayed in Table 9 for the entire data set.

The proliferation of taper models over the last 5 decades provides a wide variety of models that could be used to 
compare performance. Results of several applications indicates that for estimating diameter, height, and volume, the Max and Burkhart (1976) model appears to be more accurate than many other model formulations ( $\mathrm{Cao}$ et al. 1980; Martin 1981).

This equation is of the form:

$\frac{d^{2}}{D^{2}}=\beta_{1}(Z-1)+\beta_{2}\left(Z^{2}-1\right)+\beta_{3}\left(a_{1}-Z\right)^{2} I_{1}+\beta_{4}\left(a_{2}-Z\right)^{2} I_{2}$

where

$I_{i}=\left\{\begin{array}{ll}1 & Z \leq a_{i} \\ 0 & Z>a_{i}\end{array} \quad i=1,2 \quad Z=\frac{h}{H}\right.$

$a_{i}=$ join points to be estimated from the sample data; $i=1,2$.

The volume equation, derived through integration of the Max and Burkhart taper equation, is of the form:

$V=K D^{2} H\left\{\begin{array}{l}\frac{\beta_{2}}{3}\left(Z_{\mathrm{u}}^{3}-Z_{1}^{3}\right)+\frac{\beta_{1}}{2}\left(Z_{\mathrm{u}}^{2}-Z_{1}^{2}\right)-\left(\beta_{1}+\beta_{2}\right)\left(Z_{\mathrm{u}}-Z_{1}\right) \\ -\frac{\beta_{3}}{3}\left[\left(a_{1}-Z_{\mathrm{u}}\right)^{3} J_{1}-\left(a_{1}-Z_{1}\right)^{3} K_{1}\right] \\ -\frac{\beta_{4}}{3}\left[\left(a_{2}-Z_{\mathrm{u}}\right)^{3} J_{2}-\left(a_{2}-Z_{1}\right)^{3} K_{2}\right]\end{array}\right\}$

where

$Z_{1}=\frac{h_{1}}{H}, \quad Z_{\mathrm{u}}=\frac{h_{\mathrm{u}}}{H}$,

$h_{1}$ is the lower height of interest (m) and $h_{\mathrm{u}}$ is the upper height of interest $(\mathrm{m})$.

$J_{i}=\left\{\begin{array}{ll}1 & Z_{\mathrm{u}} \leq a_{i} \\ 0 & Z_{\mathrm{u}}>a_{i}\end{array} \quad i=1,2 \quad K_{i}=\left\{\begin{array}{ll}1 & Z_{1} \leq a_{i} \\ 0 & Z_{1}>a_{i}\end{array} \quad i=1,2\right.\right.$

Forest managers and researchers require simple methods of estimating tree volume for harvested trees and for those still standing. Volume equations have been used as one of the means to estimate tree and stand volumes, and have played a vital role in forest inventory, management and silvicultural research (Teshome 2005). Nowadays, there are many different forms of volume equations both linear and non-linear form. One of the most common forms is Spurr's volume equation for a linear combined variable model (Bi and Hamilton 1998). This equation has the form:

$V=a_{0}+a_{1} D^{2} H$

Variables are as previously defined.

\subsection{Criteria of model evaluation}

In this study we follow the recommendation by Kozak and Smith (1993) to evaluate the models. The statistics used to compare the models were average bias $(B)$, the standard error of the estimate (SEE) and a fit index (FI). These evaluation statistics are defined:

$B=\frac{\sum_{i=1}^{n}\left(Y_{i}-\widehat{Y}_{i}\right)}{n}$

$\mathrm{SEE}=\sqrt{\frac{\sum_{i=1}^{n}\left(Y_{i}-\widehat{Y}_{i}\right)^{2}}{n-k}}$

$\mathrm{FI}=1-\left[\frac{\sum_{i=1}^{n}\left(Y_{i}-\widehat{Y}_{i}\right)^{2}}{\sum_{i=1}^{n}\left(Y_{i}-\bar{Y}\right)^{2}}\right]$

where

$Y_{i}=$ observed value for the $i$ th observation

$\widehat{Y}_{i}=$ predicted value for the $i$ th observation

$\bar{Y}=$ mean of the $Y_{i}$ values

$k=$ number of estimated parameters

$n$ = number of observations in the data set

To concurrently minimize taper and volume errors, both equations were fitted simultaneously using the SAS PROC MODEL (SAS Institute 2002; Thomas et al. 1995). All parameters were shared by both the taper and volume equations. After an initial evaluation to determine whether individual species equations were justified, the models were independently fitted to the data for each of the five commercial species. Correlated error structure in the data was not taken into account in SAS MODEL procedure. Prediction accuracy is little affected by the correlated error structure, even when the correlated errors structure is accounted for in the equation fitting process (Williams and Reich 1997; Kozak 1997; Parresol 1999). Parameter estimates by model number for all tree species are displayed in Table 9. In comparisons, we used only results of model 1.

\section{Results}

\subsection{Taper models}

All parameters for each equation were found to be significant at the 0.0001 level. For each compatible taper 
and volume equation, overall statistics of fit ( $B$, SEE, and FI) for the entire merchantable stem were calculated and are presented in Table 3 for dob by tree species. The $B$ was positive for taper models and four tree species, which indicates that diameter was underestimated except for Black pine. The results indicate that the Clark et al. (1991) model was superior to the Max and Burkhart model (1976) in predicting dob. Equation 1 explained more than $98 \%$ of the total variation for predicting upper stem diameter for all tree species. Most residuals clustered around 0 (Fig. 2), indicating that the model was unbiased and there was no apparent increase in error variance with increasing tree size. Equation 4 had higher SEE values for dob for all tree species. This statistic suggests that Eq. 1 was better than Eq. 4. For Equation 1, the estimated SEE are approximately $1.5 \mathrm{~cm}$ for each species, and these values are significantly lower than for Eq. 4.

Equations 1 and 4 were further evaluated by examining the statistics of fit by relative height $\left(\frac{h}{H}\right)$ classes in order to evaluate their performance at different positions throughout the merchantable stem. Statistics by relative heights for Eqs. 1 and 4 are given in Tables 4 and 5. Average $B$ and SEE were calculated for each equation by relative height class along the merchantable stem and used to evaluate taper and volume estimates for all tree species. The results indicated that Eq. 1 performed better than Eq. 4 for each section and did not exhibit large variation in any section when estimating dob. For relative height class 50-80\%, Eqs. 1 and 4 showed larger standard errors of the estimate than at other height intervals. This relative height class is associated with point that was equivalent to the base of the live crown for most sample trees in all tree species. However, SEE in predicting diameter was relatively small near the bottom of the bole for all tree species. The proposed equations showed consistent sectional performance for each species in the validation data set. Overall, biases and average errors (SEE) were lower in validation data set than the model development data set for the five species.

\subsection{Volume predictions}

The Clark et al. (1991) compatible cubic meter volume function was compared to the compatible volume equation published by Max and Burkhart (1976). For both Eqs. 2 and 5, statistics of fit ( $B, \mathrm{SEE}$, and FI) for total stem volume (over bark) are presented in Table 3. Equations 2 and 5 had average biases less than $0.002 \mathrm{~m}^{3}$ for volume over bark. Two models tended to underestimate volume except Eq. 2, which overestimated volume over bark for Black pine. SEE for Eq. 2 was significantly lower than that in Eq. 5. The volume equations based on taper in Eqs. 1 and 4 explained more than $98 \%$ of the variation for predicting volume for the five species. The results indicate that Eq. 2 had better overall prediction statistics for volume with lower average biases, SEE and higher FI values than the Max and Burkhart (1976) model. The estimated SEE were less than $0.006 \mathrm{~m}^{3}$ for all tree species. Volume predictions by relative height classes were also evaluated for Eqs. 2 and 5 in Tables 6 and 7. Equation 2 gave better over bark volume predictions for most sections with lower biases and SEE, and higher FI values than Eq. 5. For Eq. 2, the maximum error (SEE) was $0.0086 \mathrm{~m}^{3}$ for Brutian pine, $0.0052 \mathrm{~m}^{3}$ for

Table 3 Total stem fit statistics for the compatible volume and taper equation systems for the five tree species based on model fitting data

\begin{tabular}{|c|c|c|c|c|c|c|}
\hline \multirow[t]{2}{*}{ Tree species } & \multicolumn{3}{|c|}{ Taper $(\mathrm{cm})$} & \multicolumn{3}{|c|}{ Volume $\left(\mathrm{m}^{3}\right)$} \\
\hline & $\mathrm{B}$ & SEE & FI & $\mathrm{B}$ & SEE & FI \\
\hline \multicolumn{7}{|l|}{ Brutian pine } \\
\hline Clark et al. model & 0.2445 & 1.6335 & 0.9854 & 0.0005 & 0.0058 & 0.9906 \\
\hline Max and Burkhart model & 0.4527 & 2.0517 & 0.9770 & 0.0011 & 0.0080 & 0.9821 \\
\hline \multicolumn{7}{|l|}{ Lebanon cedar } \\
\hline Clark et al. model & 0.1398 & 1.1508 & 09876 & 0.0003 & 0.0032 & 0.9923 \\
\hline Max and Burkhart model & 0.3670 & 1.2870 & 0.9845 & 0.0009 & 0.0043 & 0.9859 \\
\hline \multicolumn{7}{|l|}{ Cilicica fir } \\
\hline Clark et al. model & 0.1652 & 0.9201 & 0.9951 & 0.0001 & 0.0038 & 0.9954 \\
\hline Max and Burkhart model & 0.5698 & 1.6528 & 0.9843 & 0.0012 & 0.0074 & 0.9843 \\
\hline \multicolumn{7}{|l|}{ Scots pine } \\
\hline Clark et al. model & 0.1129 & 1.1561 & 0.9847 & 0.0004 & 0.0033 & 0.9876 \\
\hline Max and Burkhart model & 0.3376 & 1.3432 & 0.9793 & 0.0008 & 0.0041 & 0.9820 \\
\hline \multicolumn{7}{|l|}{ Black pine } \\
\hline Clark et al. model & -0.1739 & 1.5152 & 0.9857 & -0.0002 & 0.0050 & 0.9915 \\
\hline Max and Burkhart model & -0.0411 & 1.9268 & 0.9768 & 0.0002 & 0.0080 & 0.9786 \\
\hline
\end{tabular}



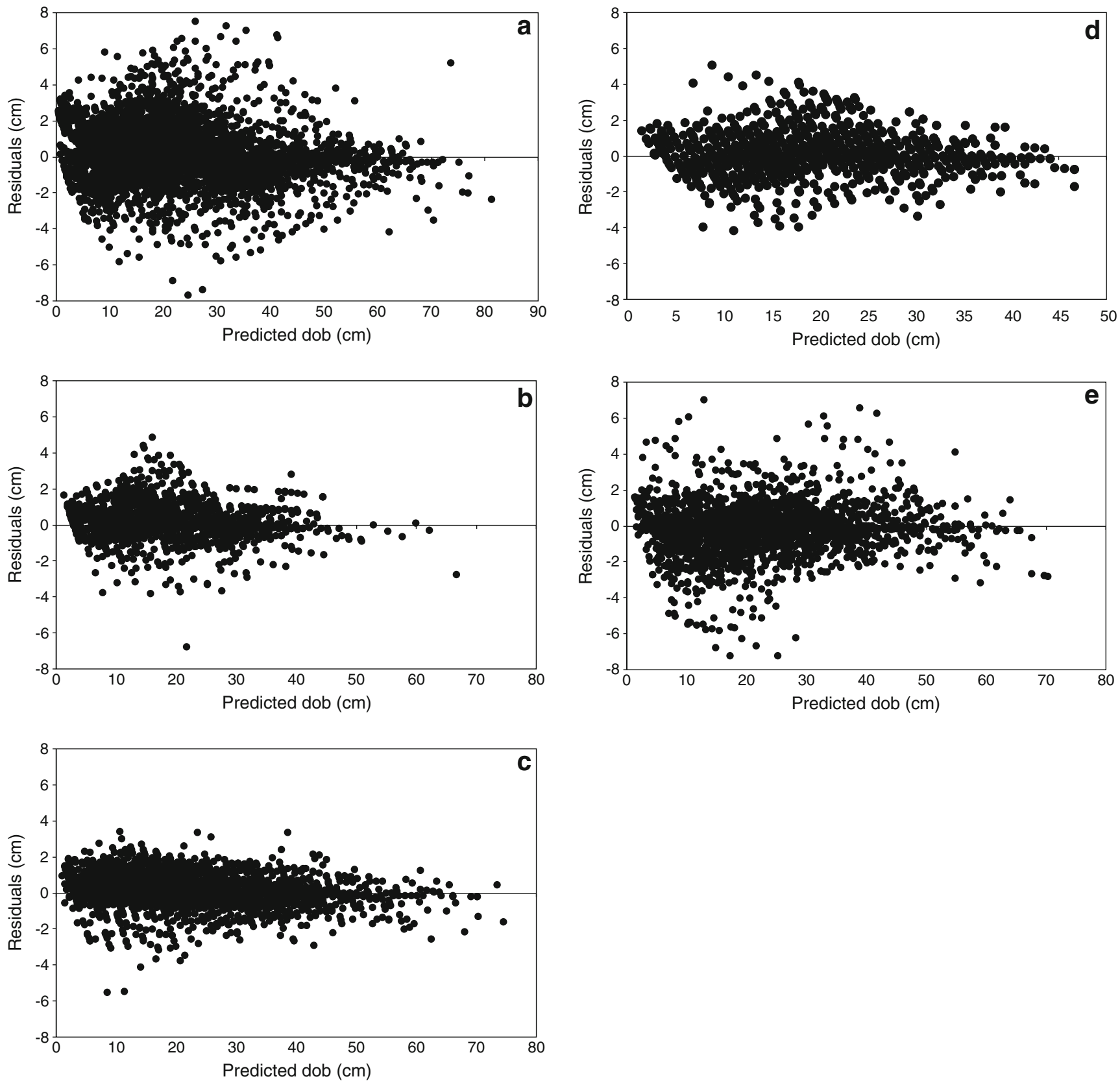

Fig. 2 Residual plots of Clark et al. (1991) taper model for Brutian pine (a), Lebanon cedar (b), Cilicica fir (c), Scots pine (d), and Black pine (e), respectively

Lebanon cedar, $0.0078 \mathrm{~m}^{3}$ for Cilicica fir, $0.0053 \mathrm{~m}^{3}$ for Scots pine, and $0.0078 \mathrm{~m}^{3}$ for Black pine, while the maximum error of Eq. 5 was $0.0102 \mathrm{~m}^{3}$ for Brutian pine, $0.0055 \mathrm{~m}^{3}$ for Lebanon cedar, $0.0101 \mathrm{~m}^{3}$ for Cilicica fir, $0.0053 \mathrm{~m}^{3}$ for Scots pine, and $0.0095 \mathrm{~m}^{3}$ for Black pine. For the validation data set, the Clark et al. model showed better over bark volume prediction for most sections with lower biases and SEE than Max and Burkhart's model.

The estimated parameter values of Spurr's combined variable equation for Brutian pine, Lebanon cedar, Cilicica fir, Scots pine, and Black pine were defined using model fitting data (Table 10). The performance of this model was compared to the Clark et al. (1991) model using the validation data set. A plot of total volume residuals for these models indicated that differences were minimal for Brutian pine. However, Spurr's volume model prediction errors for the other tree species were found to be larger than those for the Clark et al. (1991) model (Fig. 3). Total volume residuals for tested models in Fig. 3 are given only for Brutian pine, Cilicica fir, and Black pine. The Spurr's model overestimated volume for all tree species but had the lowest average bias of all models for volume over bark 

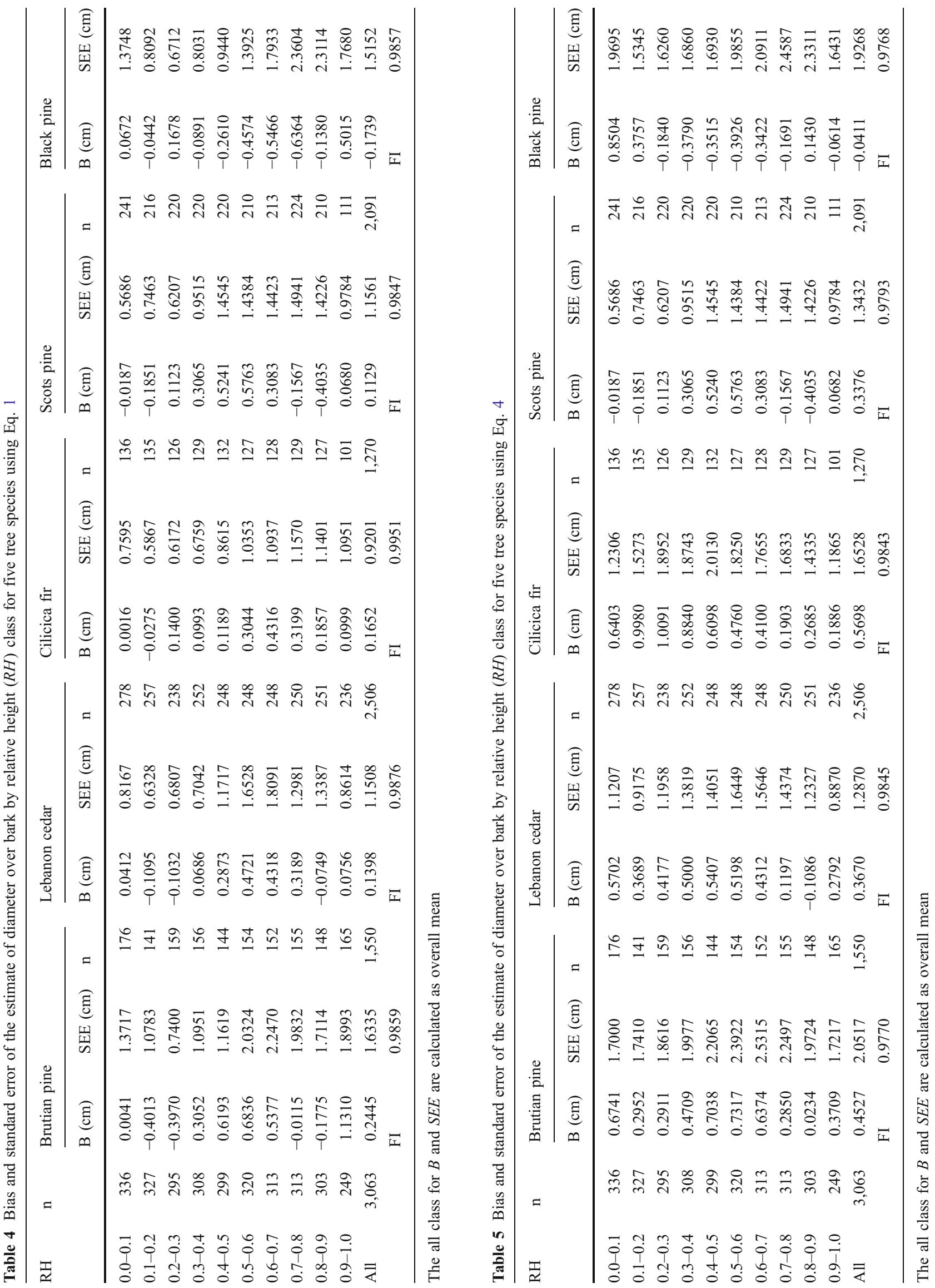

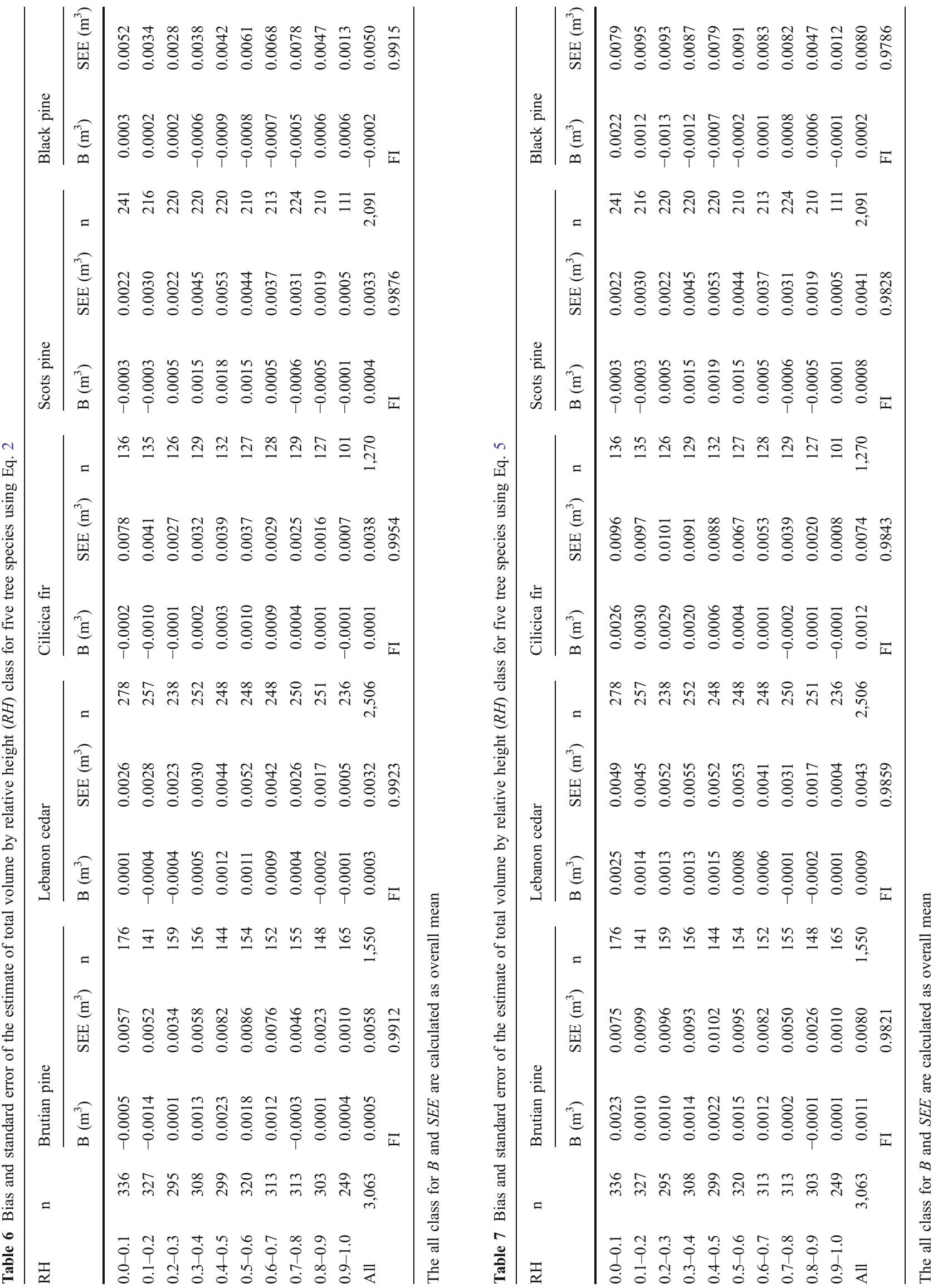

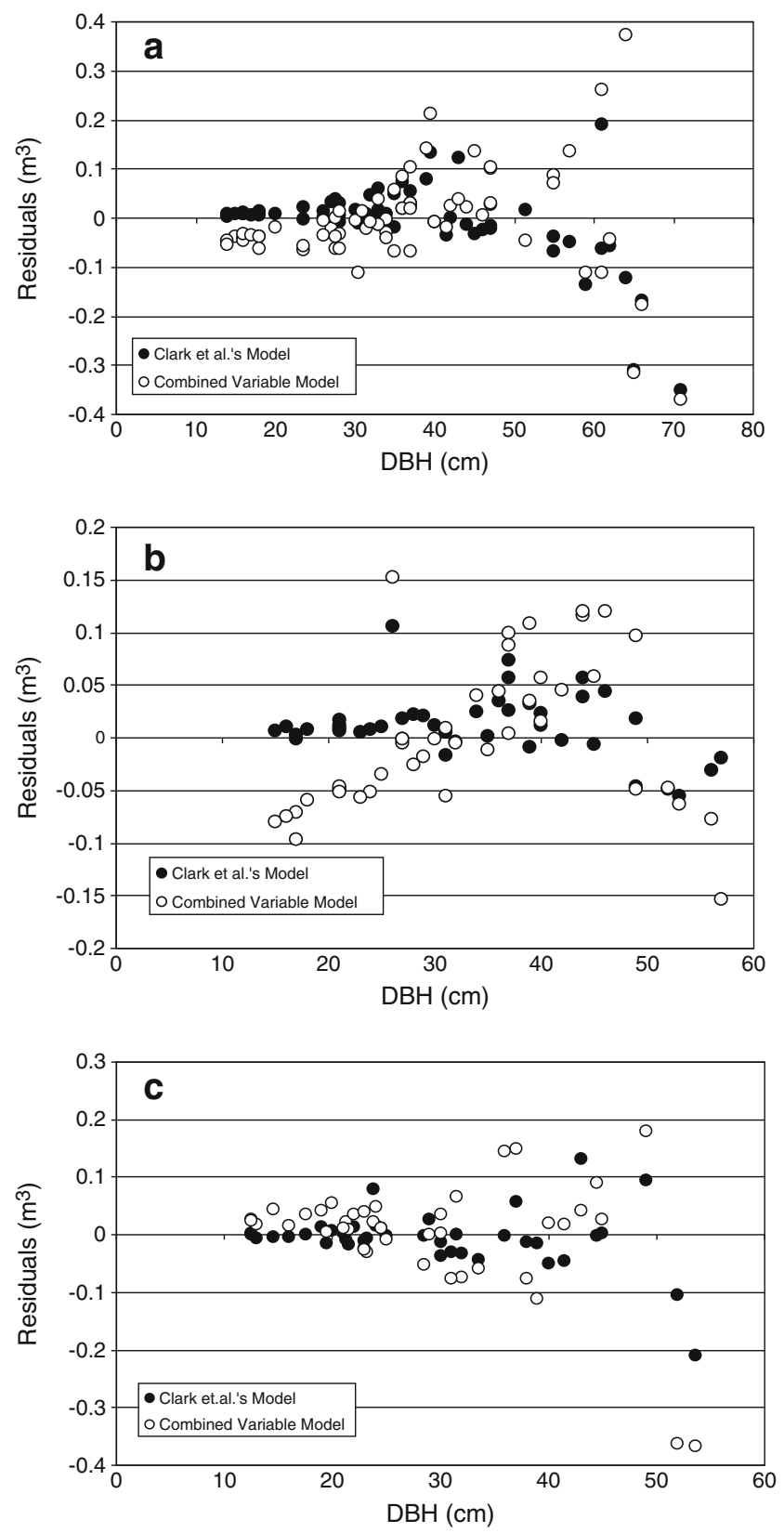

Fig. 3 Total volume residuals (validation data) for the proposed Clark et al. (1991) model and Spurr's combined variable equation for a Brutian pine, b Cilicica fir, and c Black pine, respectively

(Table 8). One possible reason might be that large positive and negative biases cancelled each other resulting in a low average bias. Therefore, SEE was used to further evaluate the performance of these models. The models with the lowest SEE are considered best as suggested by Jiang (2004). The results indicate that the volume systems of Clark et al. (1991) performed better than Spurr's volume equation, which clearly overestimated the volumes of the largest trees (Fig. 3).

In order to assess the performance of the proposed equation relative to the existing total volume tables for Brutian pine
Table 8 Comparison of total volume, bias and SEE for the proposed models, Spurr's volume equation, and existing total stem volume table estimates based on the validation data set

\begin{tabular}{lcc}
\hline Species & Bias $\left(\mathrm{m}^{3}\right)$ & SEE $\left(\mathrm{m}^{3}\right)$ \\
\hline Brutian pine & & \\
Clark et al. model & -0.0051 & 0.0787 \\
Existing volume table & -0.0436 & 0.1380 \\
Spurr model & -0.0046 & 0.1062 \\
Lebanon cedar & & \\
Clark et al. model & 0.0088 & 0.0282 \\
Existing volume table & -0.0377 & 0.0691 \\
Spurr model & -0.0021 & 0.0427 \\
Cilicica fir & & \\
Clark et al. model & 0.0112 & 0.0318 \\
Existing volume table & -0.1191 & 0.2380 \\
Spurr model & -0.0008 & 0.0703 \\
Scots pine & & \\
Clark et al. Model & 0.0021 & 0.0268 \\
Existing Volume Table & -0.0101 & 0.0461 \\
Spurr Model & -0.0014 & 0.0368 \\
Black pine & & 0.0509 \\
Clark et al. model & -0.0061 & 0.1279 \\
Existing volume table & -0.0668 & 0.0001 \\
Spurr model & & \\
\hline
\end{tabular}

(Alemdağ 1962), Lebanon cedar (Evcimen 1963), Cilicica fir (Bozkuş and Carus 1997), Scots pine (Alemdağ 1967), and Black pine (Gulen 1959) total volume estimates were compared with actual bole volumes based on the validation data set. For all trees in the validation data set, the proposed Clark et al. (1991) model and the Spurr model exhibited lower bias and SEE than existing volume tables (Table 9). These differences were small for Scots and Lebanon cedar but for Cilicica fir, the SEE for the proposed model was more than one-quarter the size of that for the existing volume table. On the other hand, Spurr's volume equation, predictions of total volume were slightly better than currently employed volume tables for all tree species (Table 8).

Finally, the proposed taper and volume models were refit to the entire data set (model fitting and validation data sets). The resultant parameter estimates by species are provided in Table 9 .

\section{Discussion}

Taper equations are invaluable tools in forestry, but selecting an appropriate model that works well across multiple species and various stand conditions can be difficult because of the variety of forms that are currently available. In this study, of five economically important five tree species in Turkey, we 
Table 9 Parameter estimates for the compatible taper and volume equations for economically important tree species based on all sample data

\begin{tabular}{lrllllll}
\hline Model & $\mathrm{r}$ & $\mathrm{c}$ & $\mathrm{e}$ & $\mathrm{p}$ & $\mathrm{a}$ & $\mathrm{b}$ & $\mathrm{b}_{1}$ \\
\hline Model 1 & & & & & & & \\
Brutian pine & 11.5135 & 0.2501 & 1069.923 & 3.1086 & 0.8355 & 2.1099 & \\
Lebanon cedar & 4.7271 & 0.2017 & 2203.949 & 1.3455 & 1.0220 & -8.0195 & \\
Cilicica fir & 5.2524 & 0.1783 & 1218.746 & 2.3669 & 0.9861 & 10.3318 & \\
Scots pine & 7.5552 & 0.1565 & 1412.678 & 4.1543 & 0.9319 & 5.5064 & \\
Black pine & 11.9387 & 0.1977 & 3030.905 & 6.6283 & 0.7775 & 3.1583 & \\
Model 2 & & & & & & & 0.8626 \\
Brutian pine & 11.4017 & 0.2540 & 1011.186 & 2.3083 & 0.8121 & 2.0202 & -0.7413 \\
Lebanon cedar & 5.4615 & 0.2082 & 2092.052 & 4.7690 & 1.0171 & -11.0719 & 0.8654 \\
Cilicica fir & 16.7668 & 0.1946 & 2060.795 & 2.8190 & 0.9879 & 11.9823 & -0.6268 \\
Scots pine & 7.9374 & 0.1683 & 1347.738 & 4.0489 & 0.9281 & 5.5458 & 0.8606 \\
Black pine & 14.6912 & 0.2212 & 2919.034 & 5.3852 & 0.7742 & 3.1097 & -0.7317 \\
\hline
\end{tabular}

For Model 1, $F$ values were obtained through actual measurements; for Model 2, $F$ values were predicted for each tree species using the proposed equation by Clark et al. (1991)

compared two taper equations, Spurr's volume equation, and existing volume tables in the same manner as $\mathrm{Li}$ and Weiskittel (2010). Across the species, the taper equation of Clark et al. (1991) was identified as the most reliable and accurate taper equation for prediction of both dob and total stem volume.

According to Kozak and Smith (1993), both practical and statistical considerations should be taken into account when choosing a taper estimating system for operational applications. Both biases and standard errors of estimate should be evaluated for all attributes of interest. Also, the biases and standard errors of estimate should be evaluated for different portions of the stem. The overall statistics of fit ( $B$, SEE, and FI) and residual plots for the entire merchantable stem were calculated and presented in Table 3 and Fig. 2 for the equations tested. The results indicate that the Clark et al. (1991) model explained more than $98 \%$ of the total variation for predicting upper stem diameter, indicating a good agreement between observed and predicted dob for all tree species.

In comparison to the Max and Burkhart (1976), Jiang et al. (2005) found that the Clark et al. (1991) reduced the standard error of estimate by $16-23 \%$ in predicting dob and dib (diameter inside bark) of yellow-poplar. In predicting dob and volume in this study, Clark et al. (1991) equation reduced the SEE average by between $22 \%$ and $30 \%$ when compared to Max and Burkhart's model. Based on our study, the Clark et al.'s model showed good performance in terms of overall fir statistics and residual plots, sectional performance, $B$ and $S E E$ in estimating diameter and volume, respectively.

The performance of the proposed equation was also compared to the Spurr (1952) volume equation using the validation data set. Compared with the Spurr (1952) volume equation, the Clark et al. taper equation in our study has better predictive ability for estimating individual tree stem volume. However, average bias for Spurr's model was consistently less than $0.005 \mathrm{~m}^{3}$, which was slightly lower than the Clark et al. model taper equation. A lower bias cannot guarantee good performance of the model because large positive and negative biases may cancel each other. The SEE for the Clark et al. model was significantly lower than for Spurr's model and in particular, Spurr's volume equation overestimated the total volume of the largest trees. Therefore, prediction errors were generally larger in larger diameter trees.

The Clark et al. (1991) model performed better than currently employed volume tables when estimating merchantable volumes, particularly the larger top diameter merchantability limits. This is a good characteristic from a practical or economic point of view. For all trees in the validation data set, the proposed model Equation 2 exhibited lower bias and
Table 10 Parameter estimates for combined variable model for economically important tree species based on all sample data

\begin{tabular}{llllll}
\hline Parameter & Brutian pine & Lebanon cedar & Cilicica fir & Scots pine & Black pine \\
\hline$a_{0}$ & 0.0667 & 0.0863 & 0.1003 & 0.0691 & -0.0299 \\
$a_{1}$ & 0.000030 & 0.000030 & 0.000028 & 0.000031 & 0.000037 \\
\hline
\end{tabular}


SEE than current volume tables. In addition to providing as good or better total volume estimates, the proposed models can also be utilized to predict product volumes to any desired top diameter limit and permit multi-product volume estimation for the same tree, a feature not supported in the existing total stem volume tables.

However, in addition to requiring as input the diameter at breast height (DBH) and total height, the Clark et al. (1991) model form requires the diameter at $5.30 \mathrm{~m}$. Although it is now easier to estimate this variable in the field using equipment such as the Criterion RD 1000 (Laser Technology Inc., Centennial, CO, USA), a prediction equation was presented to estimate this variable. Our results indicate that although the estimates were less accurate when this variable is predicted rather than measured, the results were still more accurate than the Max and Burkhart (1976) model form, the Spurr (1952) combined variable volume equation (Table 10), or the existing standard volume tables for these species. Similar results were also reported by Figueiredo-Filho et al. (1996) and Jiang et al. (2005).

Based on the results obtained, it is recommended that the Clark et al. (1991) taper and compatible volume models be considered for operational use for Brutian pine, Lebanon cedar, Cilicica fir, Scots pine, and Black pine in Turkey.

Acknowledgements We would like to thank Dr. Harry V. Wiant Jr. for his valuable comments on the earlier drafts of the manuscript and for revising the English grammar of the text. Special thanks to the Associate Editor, Barry Gardiner, and two anonymous reviewers for their constructive comments and suggestions.

Funding This study was supported by The Scientific and Technological Research Council of Turkey (TUBITAK-BIDEB).

\section{References}

Alemdağ Ș (1962) Development, yield and management rules of Brutian pine (Pinus brutia Ten.) forests in Turkey. Forestry Research Publication, Technical Bulletin Ankara, 160 pp

Alemdağ Ș (1967) Structure and yield potential of Scots pine (Pinus sylvestris L.) forests in Turkey and the principles to be followed in managing these forest. Forestry Research Publication, Technical Bulletin Ankara, $160 \mathrm{pp}$

Anonymous (2006) Forest resources. The General Directorate of Forests, Ankara, $159 \mathrm{pp}$

Bailey RL (1995) Upper stem volumes from stem analysis data: an overlapping bolts method. Can J For Res 26:170-173

Bi H (2000) Trigonometric variable-form taper equations for Australian eucalyptus. For Sci 46:397-409

Bi H, Hamilton F (1998) Stem volume equations for native tree species in southern New South Wales and Victoria. Aust For 61:275-286
Bozkuș HF, Carus S (1997) Double accessed stem volume tables of Cilicica fir (Abies cilicica Carr.) and cedar (Cedrus libani A. Rich.) and the comparison of them with the ones existing. Rev Fac For Univ Istanbul 47:51-70

Brooks JR, Jiang L, Ozcelik R (2008) Compatible stem volume and taper equations for Brutian pine, Cedar of Lebanon, and Cilicica fir in Turkey. For Ecol Manage 256:147-151

Cao QV, Burkhart HE, Max TA (1980) Evaluation of two methods for cubic-volume prediction of loblolly pine to any merchantable limit. For Sci 26:71-80

Clark III A, Souter RA, Schlaegel BE (1991) Stem profile equations for southern tree species. USDA For Serv Res Pap SE-282

Clutter JL (1980) Development of taper functions from variable-top merchantable volume equations. For Sci 26:117-120

Dieguez-Aranda U, Castedo-Dorado F, Alvarez-Gonzalez JG, Rojo A (2006) Compatible taper function for Scots pine plantations in northwestern Spain. Can J For Res 36:11901205

Demaerschalk JP (1972) Converting volume equations to compatible taper equations. For Sci 18:241-245

Evcimen BS (1963) The economical value, yield, and management basis of cedar (Cedrus libani A.Rich.) forests in Turkey. General directorate of forest publications, publication No: $355 /$ $16,199 \mathrm{pp}$

Fang Z, Bailey RL (1999) Compatible volume and taper models with coefficients for tropical species on Hainan Island in Southern China. For Sci 45:85-100

Fang Z, Borders BE, Bailey RL (2000) Compatible volume taper models for loblolly and slash pine based on system with segmented-stem form factors. For Sci 46:1-12

Figueiredo-Filho A, Borders BE, Hitch KL (1996) Taper equations for Pinus taeda plantations in Southern Brazil. For Ecol Manage $83: 39-46$

Gulen I (1959) Black pine (P. nigra, Arnold.) volume table. Rev Fac For Univ Istanbul 9:97-113

Jiang L (2004) Compatible taper and volume equations for yellowpoplar in West Virginia. MS thesis, West Virginia University, Morgantown, $75 \mathrm{pp}$

Jiang L, Brooks JR, Wang J (2005) Compatible taper and volume equations for yellow-poplar in West Virginia. For Ecol Manage 213:399-409

Kozak A (1988) A variable-exponent taper equation. Can J For Res 18:1363-1368

Kozak A (1997) Effects of multicollinearity and autocorrelation on the variable-exponent taper functions. Can J For Res 27:619-629

Kozak A (2004) My last words on taper equations. For Chron 80: $507-515$

Kozak A, Smith JHG (1993) Standards for evaluating taper estimating systems. For Chron 69:438-444

Lee WK, Seo JH, Son YM, Lee KH, von Gadow K (2003) Modeling stem profiles for Pinus densiflora in Korea. For Ecol Manage 172:69-77

Li R, Weiskittel AR (2010) Comparison of model forms for estimating stem taper and volume in the primary conifer species of North American Acadian Region. Ann For Sci $67: 302-520$

Martin AJ (1981) Taper and volume equations for selected Appalachian hardwood species. USDA For Serv Res Pap NE-490

Max TA, Burkhart HE (1976) Segmented polynomial regression applied to taper equations. For Sci 22:283-289

Newnham RM (1992) A variable-form taper function four Alberta tree species. Can J For Res 22:210-223

Parresol BR (1999) Assessing tree and stand biomass: a review with examples and critical comparisons. For Sci 45:573-593 
Sakıcı OE, Misır N, Yavuz H, Misır M (2008) Stem taper functions for Abies nordmanniana subsp. bornmulleriana in Turkey. Scand J For Res 23:522-533

SAS Institute Inc. (2002) SAS/ETS User's Guide, Version 9.0, SAS Institute Inc., Cary, NC

Schlaegel BE (1983) Development of a form class taper model for Willow Oak. PhD thesis, University of Georgia, Athens, GA, $69 \mathrm{pp}$

Sharma M, Zhang SY (2004) Variable-exponent taper equations for jack pine, black spruce, and balsam fir in eastern Canada. For Ecol Manage 198:39-53

Spurr SH (1952) Forest inventory. Ronald Press, New York, 476 pp
Teshome T (2005) Analysis of individual tree volume equations for Cupressus lusitanica in Munessa forest, Ethiopia. S Afr For J 203:27-32

Thomas CE, Parresol BR (1991) Simple, flexible, trigonometric taper equations. Can J For Res 21:1132-1137

Thomas CE, Parresol BR, Le KHN, Lohrey RE (1995) Biomass and taper for trees in thinned and unthinned longleaf pine plantations. South J Appl For 19:29-35

Williams MS, Reich RM (1997) Exploring the error structure of taper equations. For Sci 43:378-386

Yavuz H, Saraçoğlu N (1999) Compatible and noncompatible stem taper equations for Alder. Turk J Agric For 23:1275-1282 